\title{
THE BENEFITS OF A PAYMENT PLAN
}

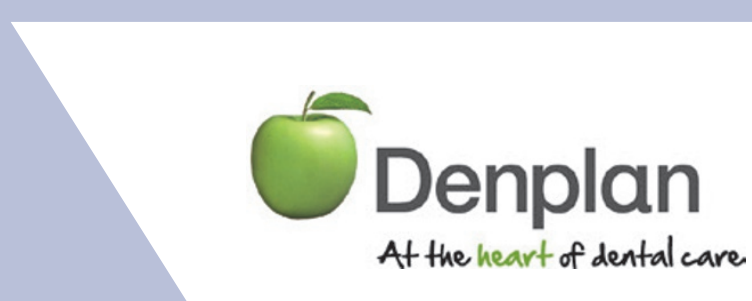

\section{FINANCIAL BENEFITS FOR YOUR PRACTICE AND FOR YOUR PATIENTS}

Partnering with a dental payment plan provider can lead to financial benefits for both your practice and your patients. This article discusses how you can make the most of your membership and achieve a level of stability that opens up long-term options, as well as the ways in which switching to private treatment via a payment plan can benefit your patients.

A payment plan might well be an option for overcoming patients' financial concerns. In fact, just over half (52\%) of NHS patients would consider paying for private dental care. ${ }^{1}$ More often than not, patients really appreciate the option of spreading the cost of treatment as well as the peace of mind that dental emergency and injury cover provides. When you communicate that, for many people, this is much less than they would spend on coffee or their mobile phone per month, for example, patients may well feel that setting money aside on a regular basis for their oral healthcare is well worth it!

A flexible payment offering can help your patients to budget for their dental care and encourage regular attendance. A recent study carried out by Denplan and YouGov found that of those respondents that have a monthly payment plan and attend the dentist at least every two years, 92\% of these actually go for check-ups at least once every six months. ${ }^{2}$ As cost is such a large factor in patient decisions, it can also help you to differentiate yourself from the competition, increasing your patient loyalty as well as the success of your practice.

Regular income via a payment plan in practice gives you a greater opportunity to put your patients at the heart of your practice, dedicate more time to each individual, treat them as you feel is clinically necessary and focus more on improving oral health through preventive dentistry.

The cornerstone of a preventive approach is full patient assessment and regular review. The frequency of these reviews can be determined by each patient's risk status, as will the time needed for other elements of preventive dentistry. Our innovative tool, Denplan/ PreViser Patient Assessment (DEPPA) provides a contemporary protocol for full patient assessment, including oral health status scoring to measure clinical outcomes, annual benchmarked reports to support clinical audit and colour-coded risk assessment reports.

DEPPA can even help you maintain effective pricing (by including an indicative Denplan fee category at each assessment). Your fees can also be calculated by your own practice's hourly rate for profitability. Further down the line, the resulting increase in stable income generated from private treatment could assist you in budgeting for fixed practice costs, renovations or even new equipment.

With so many possibilities when it comes to private payment plans, it's important to choose the path that is a good fit for you. Particularly whilst we wait to hear what form the NHS contract changes will take, now may well be the perfect time to take the leap into private dentistry if you haven't already, securing your practice income and patient wellbeing long into the future.

If you have been considering private practice for some time now but are still a little unsure, Denplan can give you the support that you need to ensure that, whatever your individual goals and aspirations may be, the transition runs as smoothly and as stress free as possible. This allows you to get back to the kind of dentistry you trained to deliver.

We offer a wide range of value added services as part of your membership, including access to a dedicated Denplan Consultant. From team training and business consultancy to marketing support and promotions, we can help you grow and develop your business. If you currently pay for these services separately, or on top of your current payment plan, hold your horses, because Denplan can provide this at no additional cost!

Members also have access to Denplan Advantage, which works in partnership with a range of businesses to provide the best deals on a variety of dental products and business services - particularly useful if you are planning a refurbishment.
Our dedicated Denplan team are there for you every step of the way when it comes to your practice. If you have any questions about what Denplan can do for you or would like to find out more, please give us a call on 08001699962.

1. Denplan/YouGov survey, January 2016. Online survey of 5,152 UK adults. All respondents who are regular attenders and NHS patients: 3,063.

2. Denplan/YouGov Survey January 2016. Online survey of 5,152 UK adults. All private patients who are regular attenders have a monthly payment plan: 280 .

\section{WHAT DENPLAN MEMBERS} SAY ABOUT US

'We've found that whatever help you want, Denplan will provide it. They have such a range of experts on board that they will always find someone who can help you with a problem. For me the best part of being in Denplan is that it is like being part of a wider, supportive network.'

Julie, Denplan dentist, Somerset

'Denplan gives you the chance to work as you were trained giving you the freedom to have the practice you want. The support in all aspects of professional practising life is superb.'

Steve, Denplan dentist,

Hampshire

'Being with Denplan has been great for helping me to budget and make improvements to the practice. Knowing what will be coming in every month allows you to plan, making life much less stressful. I've been able to use better materials and spend out on some major capital purchases.'

Peter Redfern, Denplan dentist, 